\title{
IMPORTED ZIKA VIRUS INFECTIONS IN HUNGARY BETWEEN 2016 AND 2018
}

\author{
ORSOlya NAGY ${ }^{1,2}$, ANNA NAGY ${ }^{1}$, SZILVIA TÓTH ${ }^{3}$, BERNADETT PÁlyi ${ }^{1}$, \\ ANITA VARGÁNÉ KOROKNAI ${ }^{1}$ and MÁRIA TAKÁCS ${ }^{1,2} *$ \\ ${ }^{1}$ Department of Virology, National Public Health Center, Budapest, Hungary \\ ${ }^{2}$ Institute of Medical Microbiology, Semmelweis University, Budapest, Hungary \\ ${ }^{3}$ Central Hospital of Southern Pest - National Institute of Hematology and Infectious \\ Diseases, Budapest, Hungary
}

(Received: 29 May 2018; accepted: 17 July 2019)

Zika virus is a mosquito-borne flavivirus with significant public health concern due to its association with neurological symptoms and intrauterine malformations. Although it is endemic in tropical and subtropical areas, sexual transmission raises the possibility of autochthonous spreading elsewhere. We describe the first laboratory diagnosed imported Zika-infections of Hungary, to highlight the challenges of microbiological identification of the pathogen, caused by serological cross-reactivity and short viremia. Serological examination was carried out using indirect immunofluorescent assay and enzyme-linked immunosorbent assay. Plaque-reduction neutralization test was used for verification purposes. A wide range of clinical specimens: serum, whole-blood, urine, saliva, and semen were analyzed by molecular methods, and sequencing was applied in case of PCR positive results to identify the virus strain. Zika-infected patients with previous vaccination against flaviviruses or possible flavivirus infection in the past showed high serological cross-reactivity, and even cross-neutralizing antibodies were observed. Zika virus RNA could be detected in urine specimen in case of two patients, and in EDTA-anticoagulated whole-blood sample of one patient. The detected strains belong to the Asian lineage of the virus. We presume that serological investigation of imported Zika virus could be altered by infections, vaccination of endemic flaviviruses in Hungary and vice versa.

Keywords: Zika cases, phylogenetic tree, serological cross-reactivity

*Corresponding author; E-mail: takmar@gmail.com

This is an open-access article distributed under the terms of the Creative Commons Attribution 4.0 International License, which permits unrestricted use, distribution, and reproduction in any medium, provided the original author and source are credited, a link to the CC License is provided, and changes - if any - are indicated. (SID_1) 


\section{Introduction}

Zika virus (ZIKV) is a mosquito-borne flavivirus, which, since its first isolation in 1947 in Uganda, has become a significant public health concern due to its rapid spread to new geographical areas, and it is associated with severe neurological symptoms and intrauterine malformations [1-3]. ZIKV is also capable of spreading vertically and sexually [4]; therefore, an imported infection can be passed on to others even in areas, where its vector is not present. Thus, the shedding of the virus in semen of infected men has been detected up to 370 days after onset of symptoms [5]. Although most infections are asymptomatic, when it is presented with only mild symptoms, such as low-grade fever, non-purulent conjunctivitis, headache, rash, joint, and muscle pain [6], dengue virus (DENV) and Chikungunya virus (CHIKV), which share the geographical distribution and vectors of ZIKV [7], should also be considered as causative agents. As a member of the genus Flavivirus, ZIKV is also characterized by serological cross-reactivity and short viremia that makes its identification challenging [8]. The primary vector for ZIKV is Aedes aegypti, but other Aedes mosquitoes, such as Aedes albopictus and Aedes africanus, could transmit the infection [9]. In Hungary, two Aedes species are established: Aedes japonicus [10] and Aedes koreicus [11]. A. japonicus had low potential to transmit ZIKV in recent laboratory experiments [12]. The potential of CHIKV transmission has been associated with A. koreicus [13], but, to date, no evidence of ZIKV-transmission has been described in the literature. Although the established Aedes mosquitoes of Hungary do not play a role in spreading ZIKV, vertical and sexual transmission of imported cases might occur; therefore, high vigilance and early detection of such infections are important. Considering the latest vector surveillance results, A. albopictus was introduced [14] in the southern region of the country, which raises the possibility of autochthonous transmission in the future. Moreover, in many Mediterranean countries of Europe A. albopictus, a potential vector for ZIKV, DENV, and CHIKV is established [14] and $A$. aegypti is also present in some areas, e.g., Madeira [15]. Other flaviviruses associated with human infections are endemic in Hungary: West Nile virus (WNV) [16], tick-borne encephalitis virus (TBEV) [17], and Usutu virus (USUV) [18]. Human cases of WNV and TBEV with diverse clinical symptoms occur annually $[16,17]$, while the first human USUV infection in Hungary was laboratory-confirmed during the 2018 transmission season [19]. Moreover, part of the population is immunized against TBEV [20], and vaccination against yellow fever virus (YFV) is also available related to travel. Considering these possibilities, during the diagnosis of ZIKV infections, serological analysis of other flaviviruses is important to exclude false-positive results caused by cross-reactions. Until recently, molecular 
techniques were considered to be second-line diagnostic methods for flavivirus infections due to the short viremia [21]. Recent studies describe that other clinical materials such as urine and whole-blood could be used more efficiently for nucleic acid testing because of longer virus shedding $[22,23]$.

In accordance with the European Union's case definition manual for laboratory confirmation of acute ZIKV infections [24], at least one of the following criteria must be met:

- Isolation of ZIKV from clinical specimen

- Detection of ZIKV nucleic acid or antigen in clinical specimen

- Detection of ZIKV-specific IgM antibodies in serum sample(s) and confirmation by neutralization test

- Seroconversion or fourfold increase in the titer of Zika-specific antibodies in paired sera

The aim of this study was to describe the detection of the first laboratoryconfirmed imported ZIKV-infections in Hungary and the differential diagnostic challenges of serological and molecular methods used to exclude other possible imported or endemic flavivirus infections in the country. In this publication, we describe the serological and molecular results of seven ZIKV-infected patients with different flavivirus-specific serological backgrounds.

\section{Materials and Methods}

\section{Patients}

During the 2016-2018 period, we tested samples of 603 patients (both symptomatic and asymptomatic) for ZIKV (Figure 1). Altogether seven patients had positive serological or molecular results for ZIKV, which are described in this study; in all other cases, ZIKV infection could be excluded. Every patient involved in the work traveled to areas affected with ZIKV circulation, prior to sample collection. Some patients visited different endemic regions earlier. All travelers confirmed mosquito bites as mode of transmission; other possible routes of infection (e.g., transfusion, transplantation, and sexual contact) could be excluded. Six out of seven persons experienced at least one ZIKV-specific symptom (rash or arthralgia or non-purulent conjunctivitis), four of them reported additional characteristic symptoms. One patient developed no symptoms at all. Two persons received vaccination against a flavivirus (YFV or TBEV) that may affect interpretation of the serological results due to possible cross-reactivity. Table I summarizes most important anamnestic data of investigated patients. 


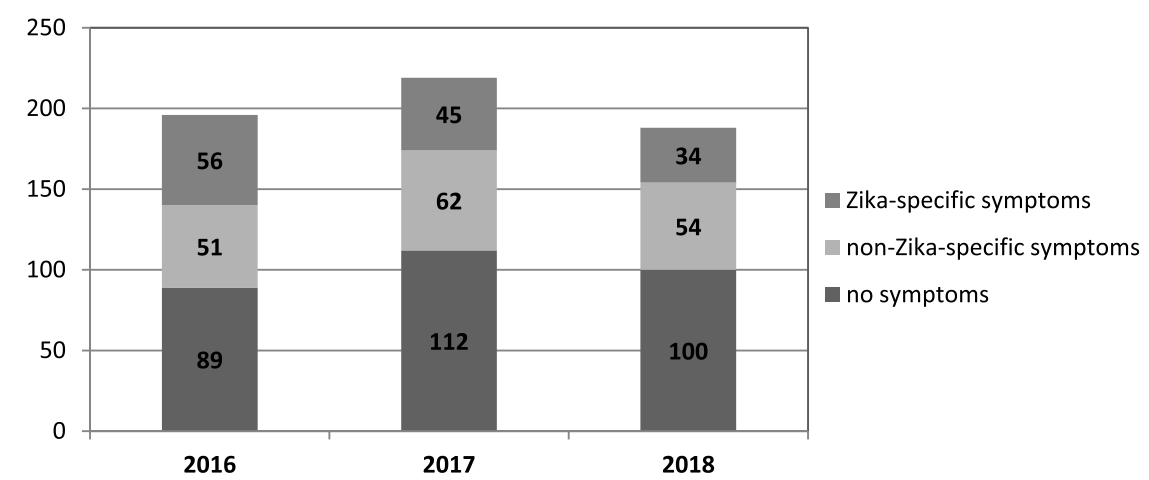

Figure 1. Distribution of the 603 cases tested for ZIKV infection between 2016 and 2018 regarding symptoms. A majority of the patients tested were symptomless and requested screening after traveling to endemic areas

\section{Serological investigation}

During serological investigation, first-line diagnostic methods for detection of flavivirus-specific antibodies were in-house immunofluorescence assay (IFA) and commercial enzyme-linked immunosorbent assay (ELISA) kit (Euroimmun Medizinische Labordiagnostika, Lübeck). In-house indirect IFA was carried out as described previously in the literature [25], with minor modification. Commercial ELISA test (Euroimmun Medizinische Labordiagnostika) was performed according to the manufacturer's instructions.

ZIKV-specific immune response was investigated in patient sera using an IFA together with ELISA kit for the detection of ZIKV-specific IgG and IgM antibodies. For verification, following the guidelines of Center for Disease Prevention and Control [26], the presence of neutralizing antibodies for both ZIKV and DENV was tested. We used an in-house plaque-reduction neutralization assay (PRNT), following the instructions of World Health Organization [27] with minor modification. As serological cross-reactivity is well known among the Flavivirus genus [8], sera were also tested for its other members: DENV - due to the shared endemic region, vectors, and symptoms with ZIKV [7], WNV, and TBEV as they are endemic in Hungary [16, 17, 28]; therefore, a possible previous infection had to be excluded. DENV-specific IgG and IgM antibodies were tested by both IFA and ELISA kit. For testing of DENV NS1 antigen, a commercial ELISA kit (Euroimmun Medizinische Labordiagnostika) was applied following the manufacturer's instructions, in case of serum specimens collected 9 days or earlier after symptom onset, based on the estimated duration time of NS1 antigen circulation in sera [29]. We used IFA to detect TBEV- and WNV-specific IgG 


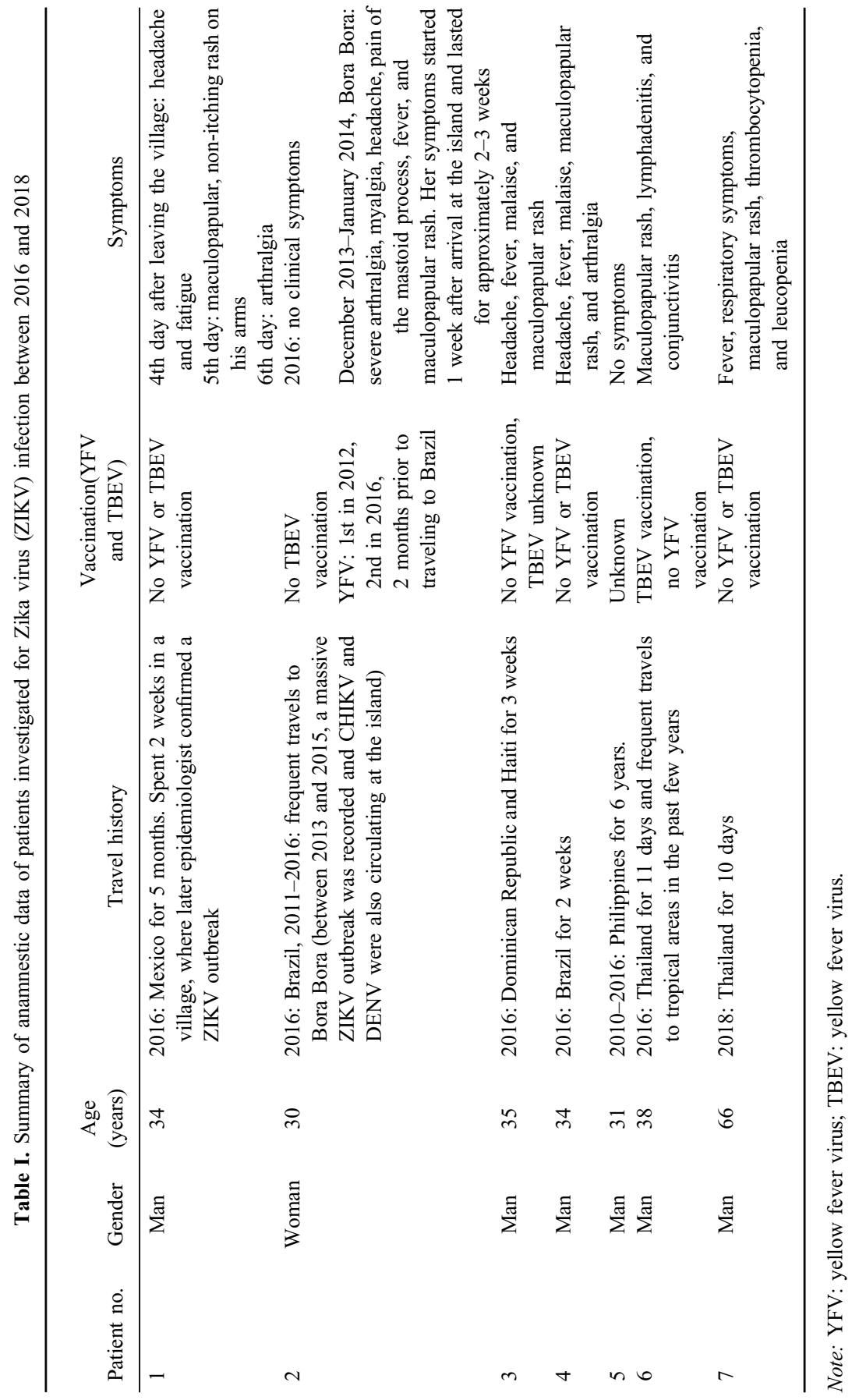


antibodies. As the first human USUV infection in Hungary was diagnosed in 2018 [19], samples collected this year were tested for USUV-specific IgG antibodies by IFA. Considering the circulation of USUV virus in birds in the country during the previous years [30], a retrospective analysis was also carried out in samples collected in 2016 and 2017, if the remaining volumes were sufficient. Taking into account the patients' travel and vaccination history, serological tests for other members of the genus Flavivirus, such as YFV, were also performed by IFA method. A possible coinfection with CHIKV, due to its shared endemic region, vectors, and symptoms with ZIKV [7], was also investigated serologically in case of every patient using commercial ELISA kit (Euroimmun Medizinische Labordiagnostika) according to the manufacturer's instructions.

\section{Molecular investigation}

For ZIKV RNA detection from human urine, serum, whole-blood, saliva, throat swab, and semen samples, total nucleic acid was extracted from $140 \mu \mathrm{l}$ of the specimens using a QIAamp Viral RNA Mini Kit (QIAGEN, Hilden) according to the manufacturer's instructions. Following a reverse-transcription step, TaqMan assay was carried out for ZIKV and DENV, respectively. The real-time RT-PCR assay for ZIKV was performed as published earlier with minor modifications [31].

In case of those patients, where elevated antibody levels were detected for both ZIKV and DENV, and time and conditions of sample collection were suitable for molecular analysis, a serotype-specific multiplex real-time RT-PCR assay was performed as published earlier [32] to exclude a possible dengue infection or coinfection.

Viral RNA from ZIKV-specific real-time RT-PCR-positive samples was also amplified using an in-house nested RT-PCR protocol with primer sets specific for the $269 \mathrm{nt}$ sequence of the NS3 and NS4A overlapping region of the viral genome (primer sequences are the following: first-round forward primer: CTGGCTTGAAGCAAGAATGC; first-round reverse primer: GGTCTCTAGGGTCTCCGGCA; second-round forward primer: CCTATCAGGTTGCATCTGCC; second-round reverse primer: AAGGCCTGCTTCCAGTCTCT). For preparation for Sanger sequencing, nested PCR amplicons were extracted using a PCR Advanced ${ }^{\mathrm{TM}}$ PCR Clean Up System (Viogen Biotek Corporation, New Taipei City, Taiwan, Republic of China) following the manufacturer's instructions. Direct sequencing of the amplicons was performed on 3500 Genetic Analyzer (Applied Biosystems, Foster City, CA, USA) using BigDye ${ }^{\circledR}$ terminator V3.1 cycle sequencing kit (Applied Biosystems), according to the manufacturer's recommendations. 
Nucleotide sequences were identified using Basic Local Alignment Search Tool (BLAST; http://blast.ncbi.nlm.nih.gov/Blast.cgi). Phylogenetic neighbor-joining tree was created by Molecular Evolutionary Genetic Analysis (MEGA) 5.05 software, using ClustalW alignments of partial segment of the NS3 and NS4A overlapping region. One thousand replicates for bootstrap testing were generated. The evolutionary distance was calculated using the Kimura 2-parameter model

\section{Virus isolation}

To attempt virus isolation, samples were filtered on 0.22 microfilter to remove any potential bacterial or fungal agents, then inoculated onto Vero cells approximately $85 \%-90 \%$ confluent after at least 1 day after seeding. After incubation for 7 days, Vero cells were harvested, and detection of viral particles was attempted by the aforementioned molecular methods.

\section{Results}

In 2016, 5 out of 196 patients had positive serological or molecular results of ZIKV. Four of them had Zika-specific symptoms and one was symptomless. In 2017, altogether 219 persons' samples were tested, and 1 symptomatic patient with ZIKV infection could be diagnosed. In 2018, one case with ZIKV-specific symptoms could be confirmed out of the 188 tested.

Summarizing, among the 603 patients tested between 2016 and 2018, 7 patients showed reactive serological results for ZIKV (Table II). No patients had antibodies against CHIKV. ELISA seemed less cross-reactive compared to IFA. In case of Patients 2, 3, and 5, serological response to a probable previous TBEV or WNV infection could be detected (Table III), but it might be a result of cross-reactivity as well. Patients 2 and 6 had history of vaccination against YFV or TBEV infection, and previous infection with other flavivirus could not be excluded according to the measured antibody levels (Table III). Although PRNT is the recommended serological method for confirmation [24], it proved to be challenging in case of secondary flavivirus infections or flavivirus infections following previous vaccination.

\section{Patient 1}

All sera of Patient 1 tested positive for ZIKV-specific IgM and $\operatorname{IgG}$ antibodies (Table II) and no significant cross-reactivity with other flaviviruses 


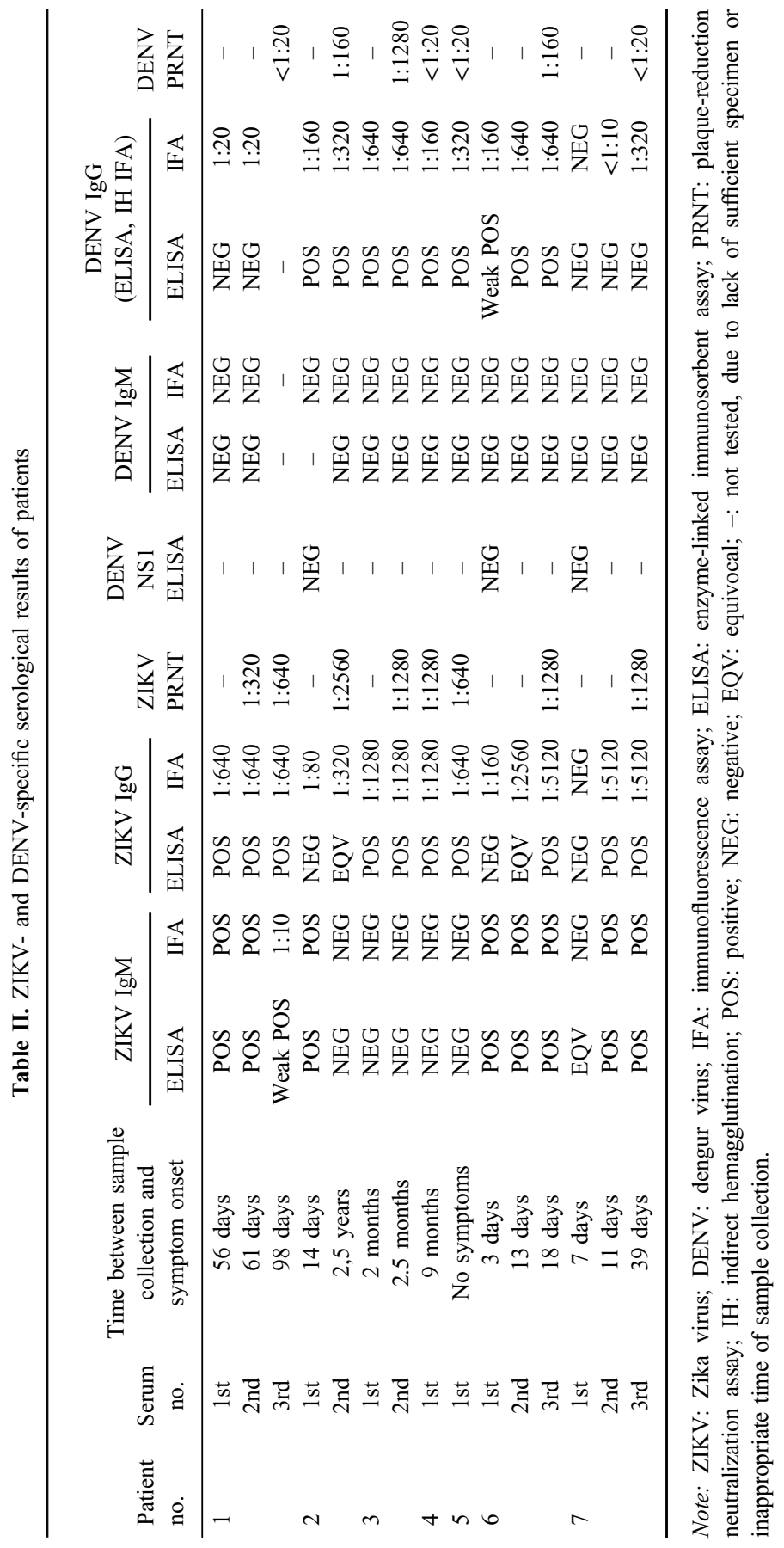




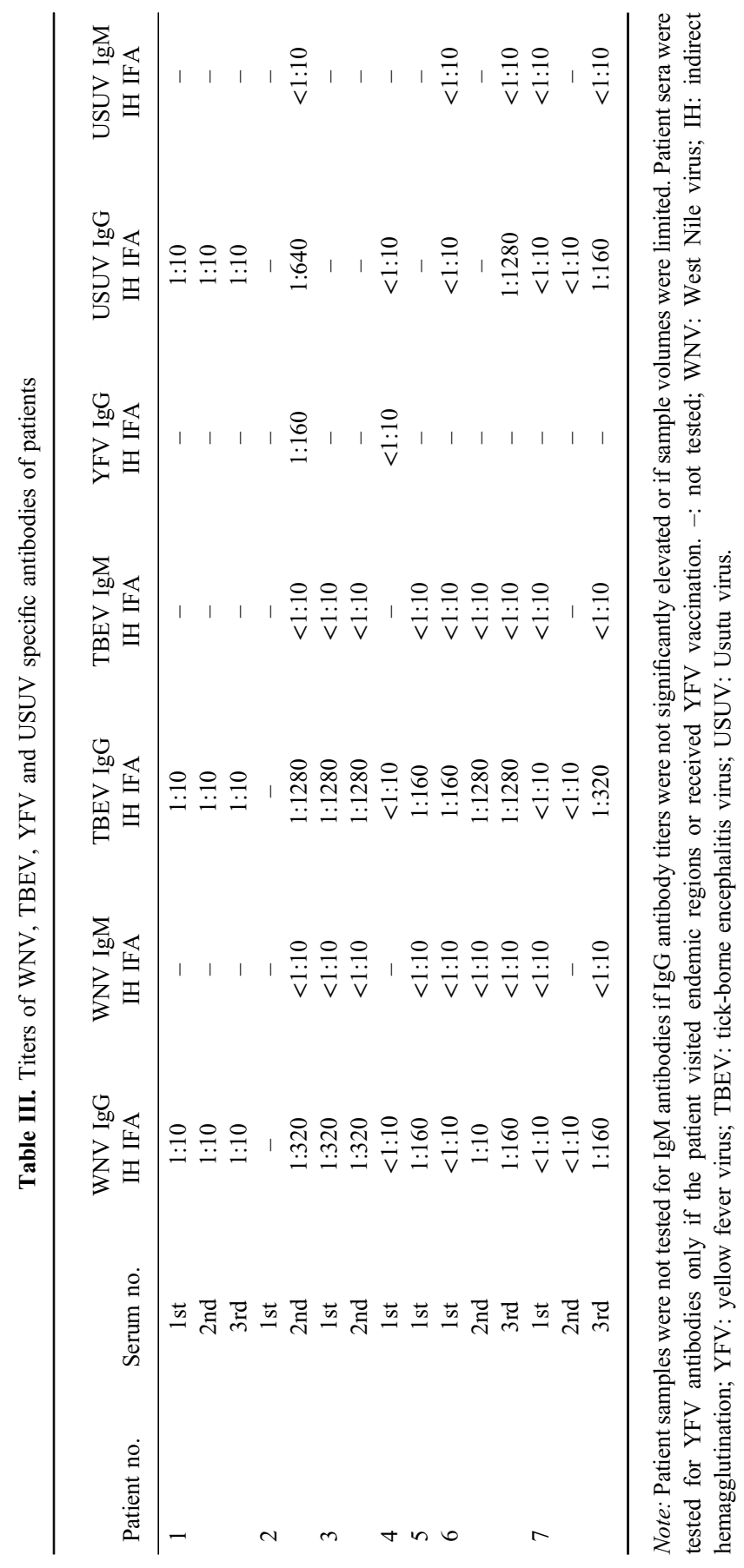


Table IV. ZIKV-specific real-time RT-PCR results of Patients 1, 2, 6, and 7 regarding the days after symptom onset

\begin{tabular}{llc}
\hline Patient & \multicolumn{1}{c}{ Sample } & ZIKV qPCR \\
\hline Patient 1 & Serum 1 (56 days), serum 2 (61 days) & Negative \\
& Urine 1 (56 days), urine 2 (61 days) & Negative \\
& Saliva (61 days), throat swab (61 days) & Negative \\
Patient 2 & Semen 1 (63 days), semen 2 (71 days), semen 3 (78 days) & Negative \\
& Serum 1 (2014), serum 2 (2016) & Negative \\
Patient 6 & Urine (2016) & Negative \\
& Serum 1 (3 days), serum 2 (14 days) & Negative \\
& Urine 1 (3 days) & Positive \\
& Urine 2 (14 days) & Negative \\
Patient 7 & Saliva (14 days), throat swab (14 days) & Negative \\
& Serum (7 days) & Negative \\
& Whole blood (7 days) & Positive \\
& Urine (7 days) & Positive \\
& Whole blood (14 days) & Negative \\
\hline
\end{tabular}

Note: Positive results are in bold to highlight the specimen types with detectable level of viral RNA. ZIKV: Zika virus; qPCR: quantitative polymerase chain reaction.

were observed (Tables II and III). PRNT assay was carried out for verification and revealed high-neutralizing titer for ZIKV (Table II). No ZIKV RNA could be detected from clinical specimens of the patient (Table IV), as remarkable time passed between onset of symptoms and sample collection.

\section{Patient 2}

With history of previous YFV vaccinations and a possible former Zika or dengue infection, Patient 2 has elevated level of neutralizing antibodies for both ZIKV and DENV (Table II). Even though a fourfold titer difference could be observed between the results of ZIKV and DENV PRNT, considering the complex serological results, including the presence of anti-ZIKV IgM antibodies in the first serum of the patient, the possibility of an acute DENV infection after a previous ZIKV infection could not be excluded as the original antigenic sin phenomenon may lead to increased antibody titers of the previous infection [33, 34]. Moreover, previous infection with other flavivirus could not be excluded either according to the measured antibody levels (Table III), but it might be a result of serological cross-reactivity.

\section{Patient 3}

Neutralizing antibody titers for ZIKV and DENV are also elevated in case of Patient 3 (Table II), who reported no previous flavivirus vaccination, but 
coinfection or earlier infection with DENV or ZIKV during prior travels to endemic regions might have occurred. Moreover, IgM antibodies were not detected in serum of Patient 3 neither for ZIKV, nor for DENV, which is a common observation in case of secondary flavivirus infections $[35,36]$. TBEV- and WNV-specific IgG antibodies were detected by indirect hemagglutination (IH) IFA in all sera of the patient (Table III) that may refer to cross-reaction or previous infection. Even the role of TBEV vaccination early in childhood could not be ruled out, as the patient had no information on his childhood vaccinations.

\section{Patient 4}

Serum collected 9 months after symptom onset was tested positive for ZIKV-specific IgG antibodies and was confirmed by PRNT. No ZIKV-specific IgM antibodies could be detected. Although serum investigated by IH IFA and ELISA methods also proved to be positive for DENV-specific IgG antibodies, it was considered a result of cross-reactivity, as DENV PRNT assay excluded a former DENV infection (Table II). Cross-reactivity with endemic flaviviruses of Hungary was not observed during the serological analysis (Table III).

\section{Patient 5}

Serum of Patient 5 was tested positive for ZIKV-specific IgG antibodies and was confirmed by PRNT. No ZIKV-specific IgM antibodies could be detected. Same as in case of Patient 4, serum investigated by IH IFA and ELISA methods also proved to be positive for DENV-specific IgG antibodies, but it was considered a result of cross-reactivity, as DENV PRNT assay excluded a former DENV infection (Table II). Cross-reactivity with endemic flaviviruses of Hungary was not observed during the serological analysis (Table III).

\section{Patient 6}

Sera of Patient 6 were tested positive for ZIKV-specific IgM antibodies and more than fourfold titer increase could be observed by serological analysis in sera collected 2 weeks apart. All sera of the patient were tested positive for DENV-specific IgG antibodies with fourfold titer difference in first and second 
sera. No DENV-specific IgM antibodies could be detected in any of his sera. PRNT testing of third serum of the patient also gave controversial results: ZIKV and DENV neutralizing antibodies could be detected in different titers (Table II). As the patient received TBEV vaccination and reported recent travels to DENV endemic regions, both cross-reaction or a previous DENV infection could explain the reactive results. Although Patient 6 has history of vaccination against TBEV, previous infection with other endemic flavivirus of Hungary could not be excluded either according to the measured antibody levels (Table III).

Patient 6 has detectable level of ZIKV RNA in his first urine sample. Second urine sample collected 3 days later, along with sera, saliva, and throat swab samples of the patient proved to be negative for ZIKV RNA using real-time RTPCR method (Table IV). PCR positive results were confirmed using in-house nested RT-PCR and Sanger sequencing. Phylogenetic analysis based on the NS3 and NS4 overlapping regions of the viral RNA obtained from sample of Patient 6 revealed close relationship with virus strains from Thailand and Singapore (GenBank accession number: MG266396) (Figure 2). Virus isolation was attempted using Vero cell lines, but no infectious virus particles were recovered.

\section{Patient 7}

First serum of Patient 7 was tested negative for ZIKV-specific IgG antibodies by both IH IFA and ELISA methods. ELISA gave an indeterminate result for ZIKV-specific IgM antibodies. During the analysis of the second and third sera of the patient, seroconversion could be observed, as high levels of IgG antibodies were detected and IgM tests also gave positive results. Crossreactive antibodies were detected from third serum specimen of the patient by IFA as PRNT excluded DENV infection (Table II). A possible acute infection of TBEV, WNV, and USUV could also be excluded based on the incubation time, absence of IgM antibodies, and moderated IgG titers (Table III). In case of Patient 7, ZIKV RNA could be detected in first whole blood and urine specimen, while first serum and second whole blood were tested negative by real-time RT PCR assay. (Table IV). PCR positive results were confirmed using in-house nested RT-PCR and Sanger sequencing. Phylogenetic analysis based on the NS3 and NS4 overlapping regions of the viral RNA obtained from samples of Patient 7 revealed close relationship with virus strains from Thailand and Singapore (GenBank accession number: MK434848) (Figure 2). Virus isolation was attempted using Vero cell lines, but no infectious virus particles were recovered. 


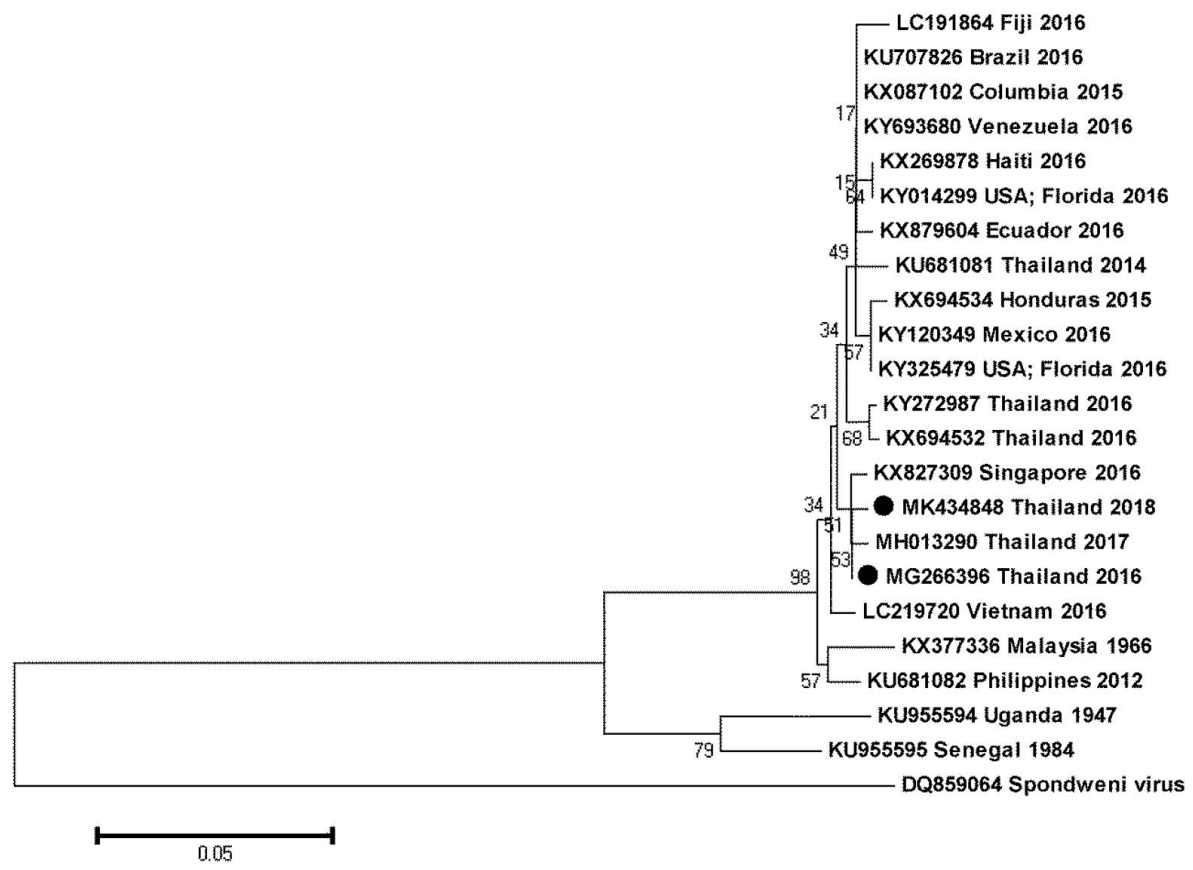

Figure 2. Phylogenetic neighbor-joining tree of ZIKV strains detected in specimens of Patient 6 (GenBank: MG266396) and Patient 7 (GenBank: MK434848), marked by black dots. The GenBank accession numbers, countries where it is identified and year of detection, are indicated in the tree. Phylogenetic neighbor-joining tree was created by Molecular Evolutionary

Genetic Analysis (MEGA) 5.05 software, using ClustalW alignments of 269-nt-long partial segment of the NS3 and NS4A overlapping region. One thousand replicates for bootstrap testing were generated. The evolutionary distance was calculated using the Kimura

2-parameter model

\section{Discussion}

Evaluation of serological and molecular results of the patients is discussed in this section.

Considering the patients' medical and travel history, symptoms, and the available epidemiological data together with the microbiological results, acute ZIKV infection could be confirmed in case of Patients 1, 6, and 7. Previous ZIKV infection was diagnosed in case of Patients 4 and 5. Based on the complex serological results and anamnestic data of Patient 2, a previous DENV or ZIKV infection or coinfection could be suspected during her stay in 2013-2014 in Bora Bora. Considering the PRNT and IgM results of Patient 3, a recent ZIKV infection after a former DENV infection or a recent DENV infection following a previous ZIKV is presumed. 
Previously described results help demonstrating the difficulties of serological diagnosis of ZIKV infection as a secondary flavivirus infection after either other imported or endemic flavivirus infections or vaccination. These challenges seem to play an important role in laboratory diagnosis even in those regions, where ZIKV is not circulating, but other flaviviruses are present. Moreover, findings of molecular analysis enhance the importance of proper timing of sample collection for molecular testing, in correlation with the duration of virus nucleic acid detection from different clinical specimens, which could explain the negative results of PCR analysis of samples collected late after symptom onset.

In the event of multiple flavivirus infections, serological results could be altered by the cross-reactive antibodies of previous infections [35, 37]. In case of $\mathrm{ZIKV}$, this phenomenon is not unusual, as this pathogen shares its endemic region with DENV, a flavivirus with $54 \%-58 \%$ homologous nucleotide sequence in the envelope protein coding region [38]. Recent studies demonstrated that in areas where dengue is present, by the time of the emergence of ZIKV, most persons have been exposed to at least one DENV serotype [39]. A majority of the screening serological methods (ELISA and immunofluorescence) are confounded by this cross-reactivity. Moreover, sera collected early after DENV infection showed cross-neutralizing effects for ZIKV and even cross-protection in animal models was reported in the literature [37, 40-43]. Not DENV is the only important flavivirus to consider when it comes to serological analysis of a possible ZIKV infection. YFV is reemerging in South America [44-46] and Africa [47-49], and a great number of travelers are immunized with the live attenuated vaccine just few weeks prior to the journey to endemic countries. In addition, a majority of the European territories are affected by one or more flaviviruses: TBEV, WNV, and USUV [16, 17, 30]; thus, these infections are mainly asymptomatic or have subclinical manifestation with no alarming symptoms [50, 51]. Given that IgM antibodies not always reach the detectable level during a secondary or multiple flavivirus infection and IgG level elevates rapidly [52], high flavivirus antibody titers are present during symptom onset and diagnosis based on only serological techniques could be challenging. Even the neutralization assays might lead to controversial results, as cross-neutralizing antibodies might occur [37]. Another characteristic phenomenon of the Flavivirus genus, the so-called original antigenic sin, also complicates the serological diagnosis; it is marked by the failure of the immune system to produce protective antibodies against a pathogen, which is antigenically related to the strain of a previous infection or vaccination of the host $[33,34]$. Moreover, this failure could be responsible for antibody-dependent enhancement (ADE) of infectivity, when cross-reactive but non-neutralizing antibodies bind to the virus and mediate endocytosis via Fc receptors into dendritic cells, macrophages, and monocytes, which lead to intracellular viral replication 
and higher viral load resulting in more severe symptoms [53, 54]. The described cases of Patients 2 and 6 support this theory: both patients were previously vaccinated by a flavivirus; thus, exposition to previous DENV infection is also possible considering the frequent travels to endemic areas. Their serological results are complex and described by cross-reactivity and elevating IgG titers for more than one flavivirus; thus, both patients belong to the minority of the population, who experience clinical symptoms during flavivirus infection.

Until recently, the molecular methods for detection of flavivirus infections were considered second-lane techniques because of the short viremia [21]. Nowadays, numerous studies highlight the importance of molecular analysis, not only to overcome the complications of the serological results, but also to monitor the epidemics and the virus evolution of these important pathogens [22]. Similarly to other flaviviruses, like WNV, longer viral RNA detection was observed in urine and whole-blood samples of ZIKV-infected patients [23, 55-58]. Additional samples, such as saliva, semen, and cervical swab, can be used for viral RNA detection for different time periods according to the literature [55]. Furthermore, elongated viral RNA positivity of maternal serum refers to intrauterine ZIKV infection, as viremia is maintained by the viral replication in the fetal tissues and the placenta [59]. Molecular examination of the amniotic fluid could be offered in such cases to confirm the diagnosis [60], especially when the serodiagnosis is altered by the pregnancy or previous flavivirus infection or vaccination. Limitations of molecular tests include the timing of sample collection, special conditions required for sample storage and transportation, and most importantly the fact that intermittent shedding of viral RNA frequently occurs [61]; therefore, repeated sample collection is desired.

In conclusion, during the serological analysis of a suspected ZIKV infection of travelers living in non-tropical countries, the serological investigation of endemic flaviviruses and the vaccination history should be underlined, because recent flavivirus infections could complicate and even cause falsepositive serological results. Although the case definition for a confirmed ZIKV infection is met in the event of a fourfold titer increase or confirmation of serological results by neutralization assay, the interpreted cases demonstrate that these criteria should be handled with caution if multiple flavivirus infections occur. On the contrary, cross-reactive antibodies of a previous ZIKV infection raise the possibility of complicating the serodiagnosis of the endemic flavivirus infections of Hungary. Anti-TBEV and anti-WNV titers of Patients 3 and 5 are elevated, although no know vaccination or previous infection is reported. The question whether the observed antibody levels are the results of a previous infection, despite the relatively moderate titers, or caused by the cross-reactive antibodies of the acute infection, needs further 
examination. The presumption that an acute ZIKV infection may alter considerably the serodiagnosis of the endemic Hungarian flaviviruses is still unclear and requires further investigation for the closer understanding of original antigenic sin and ADE of infectivity, two characteristic phenomena of the Flavivirus genus [33, 34, 54, 62].

\section{Acknowledgements}

The authors would like to thank the technical assistance of Kaposi Tamásné and Nikolett Csonka. They would also acknowledge the help of Zsófia Bognár and Eszter Mezei from the National Public Health Center, Division of Epidemiology and Infection Control for providing epidemiological data of patients.

\section{Conflict of Interest}

The authors declare no conflict of interest.

\section{References}

1. Malta, J. M., Vargas, A., Leite, P. L., Percio, J., Coelho, G. E., Ferraro, A. H., Cordeiro, T. M., Dias, J. S., Saad, E.: Guillain-Barre syndrome and other neurological manifestations possibly related to Zika virus infection in municipalities from Bahia, Brazil, 2015. Epidemiol Serv Saude 26, 9-18 (2017).

2. Avsic Zupanc, T., Petrovec, M.: Zika: An old virus with a new face. Zdr Varst 55, 228-230 (2016).

3. Mlakar, J., Korva, M., Tul, N., Popovic, M., Poljsak-Prijatelj, M., Mraz, J., Kolenc, M., Resman Rus, K., Vesnaver Vipotnik, T., Fabjan Vodusek, V., Vizjak, A., Pizem, J., Petrovec, M., Avsic Zupanc, T.: Zika virus associated with microcephaly. N Engl J Med 374, 951-958 (2016).

4. Kim, C. R., Counotte, M., Bernstein, K., Deal, C., Mayaud, P., Low, N., Broutet, N., Sexual Transmission of Zika virus expert meeting participants: Investigating the sexual transmission of Zika virus. Lancet Glob Health 6, e24-e25 (2018).

5. Barzon, L., Percivalle, E., Pacenti, M., Rovida, F., Zavattoni, M., Del Bravo, P., Cattelan, A. M., Palu, G., Baldanti, F.: Virus and antibody dynamics in travelers with acute Zika virus infection. Clin Infect Dis 66, 1173-1180 (2018).

6. World Health Organization. Zika Virus Technical Report: Interim Risk Assessment WHO European Region. WHO, Geneva, 2016. Available at http://www.euro.who.int/_data/ assets/pdf_file/0003/309981/Zika-Virus-Technical-report.pdf?ua=1

7. Paixao, E. S., Teixeira, M. G., Rodrigues, L. C.: Zika, chikungunya and dengue: The causes and threats of new and re-emerging arboviral diseases. BMJ Glob Health 3, e000530 (2018). 
8. de Vasconcelos, Z. F. M., Azevedo, R. C., Thompson, N., Gomes, L., Guida, L., Moreira, M. E. L.: Challenges for molecular and serological ZIKV infection confirmation. Childs Nerv Syst 34, 79-84 (2018).

9. Kauffman, E. B., Kramer, L. D.: Zika virus mosquito vectors: Competence, biology, and vector control. J Infect Dis 216, S976-S990 (2017).

10. European Centre for Disease Prevention and Control: Aedes japonicus - Current Known Distribution: January 2019. ECDC, Stockholm, 2019. Available at https://ecdc.europa.eu/ en/publications-data/aedes-japonicus-current-known-distribution-january-2019

11. European Centre for Disease Prevention and Control: Aedes koreicus - Current Known Distribution: January 2019. ECDC, Stockholm, 2019. Available at https://ecdc.europa.eu/ en/publications-data/aedes-koreicus-current-known-distribution-january-2019

12. Jansen, S., Heitmann, A., Luhken, R., Jost, H., Helms, M., Vapalahti, O., SchmidtChanasit, J., Tannich, E.: Experimental transmission of Zika virus by Aedes japonicus from southwestern Germany. Emerg Microbes Infect 7, 192 (2018).

13. Ciocchetta, S., Prow, N. A., Darbro, J. M., Frentiu, F. D., Savino, S., Montarsi, F., Capelli, G., Aaskov, J. G., Devine, G. J.: The new European invader Aedes (Finlaya) koreicus: A potential vector of chikungunya virus. Pathog Glob Health 112, 107-114 (2018).

14. European Centre for Disease Prevention and Control: Aedes albopictus - Current Known Distribution: January 2019. ECDC, Stockholm, 2019. Available at https://ecdc.europa.eu/ en/publications-data/aedes-albopictus-current-known-distribution-january-2019

15. European Centre for Disease Prevention and Control: Aedes aegypti - Current Known Distribution: January 2019. ECDC, Stockholm, 2019. Available at https://ecdc.europa.eu/ en/publications-data/aedes-aegypti-current-known-distribution-january-2019

16. Haussig, J. M., Young, J. J., Gossner, C. M., Mezei, E., Bella, A., Sirbu, A., Pervanidou, D., Drakulovic, M. B., Sudre, B.: Early start of the West Nile fever transmission season 2018 in Europe. Euro Surveill 23, 1800428 (2018).

17. Beaute, J., Spiteri, G., Warns-Petit, E., Zeller, H.: Tick-borne encephalitis in Europe, 2012 to 2016. Euro Surveill 23, 1800201 (2018).

18. Bakonyi, T., Erdelyi, K., Ursu, K., Ferenczi, E., Csorgo, T., Lussy, H., Chvala, S., Bukovsky, C., Meister, T., Weissenbock, H., Nowotny, N.: Emergence of Usutu virus in Hungary. J Clin Microbiol 45, 3870-3874 (2007).

19. Nagy, A., Mezei, E., Nagy, O., Bakonyi, T., Csonka, N., Kaposi, M., Szomor, K., Rigo, Z., Molnar, Z., Danielisz, A., Takacs, M.: Extraordinary increase in number of West Nile virus cases and first confirmed human Usutu virus infection in Hungary, 2018. Eurosurveillance 24, 1900038 (2019).

20. Erber, W., Schmitt, H.-J.: Self-reported tick-borne encephalitis (TBE) vaccination coverage in Europe: Results from a cross-sectional study. Ticks and Tick-borne Dis 9, 768-777 (2018).

21. van Meer, M. P. A., Mogling, R., Klaasse, J., Chandler, F. D., Pas, S. D., van der Eijk, A. A., Koopmans, M. P. G., Reusken, C., GeurtsvanKessel, C. H.: Re-evaluation of routine dengue virus serology in travelers in the era of Zika virus emergence. J Clin Virol 92, 25-31 (2017).

22. Landry, M. L., St George, K.: Laboratory diagnosis of Zika virus infection. Arch Pathol Lab Med 141, 60-67 (2017).

23. Mansuy, J. M., Mengelle, C., Pasquier, C., Chapuy-Regaud, S., Delobel, P., Martin-Blondel, G., Izopet, J.: Zika virus infection and prolonged viremia in whole-blood specimens. Emerg Infect Dis 23, 863-865 (2017). 
24. Official Journal of the European Union: Commission Implementing Decision (EU) 2018/ 945 - EUR-Lex on the communicable diseases and related special health issues to be covered by epidemiological surveillance as well as relevant case definitions. Available at https://eur-lex.europa.eu/legal-content/EN/TXT/PDF/?uri=CELEX:32018D0945\& from $=\mathrm{EN}$

25. Balogh, Z., Egyed, L., Ferenczi, E., Ban, E., Szomor, K. N., Takacs, M., Berencsi, G.: Experimental infection of goats with tick-borne encephalitis virus and the possibilities to prevent virus transmission by raw goat milk. Intervirology 55, 194-200 (2012).

26. CDC: Updated Guidance for US Laboratories Testing for Zika Virus Infection. CDC, 2017. Available at https://www.cdc.gov/zika/laboratories/lab-guidance.html

27. WHO: Guidelines for Plaque Reduction Neutralization Testing of Human Antibodies to Dengue Viruses. 2007. Available at https:/apps.who.int/iris/bitstream/handle/10665/69687/ who_ivb_07.07_eng.pdf;jsessionid=2DC5C1EC90E17510281E8F94FE4D91F2?sequence=1

28. Nagy, A., Ban, E., Nagy, O., Ferenczi, E., Farkas, A., Banyai, K., Farkas, S., Takacs, M.: Detection and sequencing of West Nile virus RNA from human urine and serum samples during the 2014 seasonal period. Arch Virol 161, 1797-1806 (2016).

29. Alcon, S., Talarmin, A., Debruyne, M., Falconar, A., Deubel, V., Flamand, M.: Enzyme-linked immunosorbent assay specific to dengue virus type 1 nonstructural protein NS1 reveals circulation of the antigen in the blood during the acute phase of disease in patients experiencing primary or secondary infections. J Clin Microbiol 40, 376-381 (2002).

30. Bakonyi, T., Erdelyi, K., Brunthaler, R., Dan, A., Weissenbock, H., Nowotny, N.: Usutu virus, Austria and Hungary, 2010-2016. Emerg Microbes Infect 6, e85 (2017).

31. Lanciotti, R. S., Kosoy, O. L., Laven, J. J., Velez, J. O., Lambert, A. J., Johnson, A. J., Stanfield, S. M., Duffy, M. R.: Genetic and serologic properties of Zika virus associated with an epidemic, Yap State, Micronesia, 2007. Emerg Infect Dis 14, 1232-1239 (2008).

32. Santiago, G. A., Vergne, E., Quiles, Y., Cosme, J., Vazquez, J., Medina, J. F., Medina, F., Colon, C., Margolis, H., Munoz-Jordan, J. L.: Analytical and clinical performance of the CDC real time RT-PCR assay for detection and typing of dengue virus. PLoS Negl Trop Dis 7, e2311 (2013).

33. Vatti, A., Monsalve, D. M., Pacheco, Y., Chang, C., Anaya, J. M., Gershwin, M. E.: Original antigenic sin: A comprehensive review. J Autoimmun 83, 12-21 (2017).

34. Haaheim, L. R.: Original antigenic sin. A confounding issue? Dev Biol (Basel) 115, 49-53 (2003).

35. Fields, B. N., Knipe, D. M., Howley, P. M.: Fields' Virology, $5^{\text {th }}$ Edition. Lippincott Williams and Wilkins, Philadelphia, PA, 2007, pp. 1153-1253.

36. Chanama, S., Anantapreecha, S., A-nuegoonpipat, A., Sa-gnasang, A., Kurane, I., Sawanpanyalert, P.: Analysis of specific IgM responses in secondary dengue virus infections: Levels and positive rates in comparison with primary infections. J Clin Virol 31, 185-189 (2004).

37. Priyamvada, L., Quicke, K. M., Hudson, W. H., Onlamoon, N., Sewatanon, J., Edupuganti, S., Pattanapanyasat, K., Chokephaibulkit, K., Mulligan, M. J., Wilson, P. C., Ahmed, R., Suthar, M. S., Wrammert, J.: Human antibody responses after dengue virus infection are highly cross-reactive to Zika virus. Proc Natl Acad Sci U S A 113, 7852-7857 (2016). 
38. Kostyuchenko, V. A., Lim, E. X., Zhang, S., Fibriansah, G., Ng, T. S., Ooi, J. S., Shi, J., Lok, S. M.: Structure of the thermally stable Zika virus. Nature 533, 425-428 (2016).

39. Castanha, P. M., Cordeiro, M. T., Martelli, C. M., Souza, W. V., Marques, E. T., Jr., Braga, C.: Force of infection of dengue serotypes in a population-based study in the northeast of Brazil. Epidemiol Infect 141, 1080-1088 (2013).

40. Barba-Spaeth, G., Dejnirattisai, W., Rouvinski, A., Vaney, M. C., Medits, I., Sharma, A., Simon-Loriere, E., Sakuntabhai, A., Cao-Lormeau, V. M., Haouz, A., England, P., Stiasny, K., Mongkolsapaya, J., Heinz, F. X., Screaton, G. R., Rey, F. A.: Structural basis of potent Zika-dengue virus antibody cross-neutralization. Nature 536, 48-53 (2016).

41. Stettler, K., Beltramello, M., Espinosa, D. A., Graham, V., Cassotta, A., Bianchi, S., Vanzetta, F., Minola, A., Jaconi, S., Mele, F., Foglierini, M., Pedotti, M., Simonelli, L., Dowall, S., Atkinson, B., Percivalle, E., Simmons, C. P., Varani, L., Blum, J., Baldanti, F., Cameroni, E., Hewson, R., Harris, E., Lanzavecchia, A., Sallusto, F., Corti, D.: Specificity, cross-reactivity, and function of antibodies elicited by Zika virus infection. Science 353, 823-826 (2016).

42. Swanstrom, J. A., Plante, J. A., Plante, K. S., Young, E. F., McGowan, E., Gallichotte, E. N., Widman, D. G., Heise, M. T., de Silva, A. M., Baric, R. S.: Dengue virus envelope dimer epitope monoclonal antibodies isolated from dengue patients are protective against Zika virus. MBio 7, e01123-e01116 (2016).

43. Zhao, H., Fernandez, E., Dowd, K. A., Speer, S. D., Platt, D. J., Gorman, M. J., Govero, J., Nelson, C. A., Pierson, T. C., Diamond, M. S., Fremont, D. H.: Structural basis of Zika virus-specific antibody protection. Cell 166, 1016-1027 (2016).

44. Selemane, I.: Epidemiological monitoring of the last outbreak of yellow fever in Brazil - An outlook from Portugal. Travel Med Infect Dis 28, 46-51 (2018).

45. Khan, A. W., Nasim, Z., Zahir, F., Khan, M. A., Ali, A., Ali, S., Khan, A. H.: Resurgence of yellow fever in Brazil: Overview and possible control options. Acta Microbiol Immunol Hung 64, 353-356 (2017).

46. Dorigatti, I., Hamlet, A., Aguas, R., Cattarino, L., Cori, A., Donnelly, C. A., Garske, T., Imai, N., Ferguson, N. M.: International risk of yellow fever spread from the ongoing outbreak in Brazil, December 2016 to May 2017. Euro Surveill 22, 30572 (2017).

47. Ingelbeen, B., Weregemere, N. A., Noel, H., Tshapenda, G. P., Mossoko, M., Nsio, J., Ronsse, A., Ahuka-Mundeke, S., Cohuet, S., Kebela, B. I.: Urban yellow fever outbreakDemocratic Republic of the Congo, 2016: Towards more rapid case detection. PLoS Negl Trop Dis 12, e0007029 (2018).

48. https://www.who.int/csr/don/09-january-2019-yellow-fever-nigeria/en/

49. https://www.who.int/emergencies/yellow-fever/situation-reports/28-october-2016/en/

50. Mostashari, F., Bunning, M. L., Kitsutani, P. T., Singer, D. A., Nash, D., Cooper, M. J., Katz, N., Liljebjelke, K. A., Biggerstaff, B. J., Fine, A. D., Layton, M. C., Mullin, S. M., Johnson, A. J., Martin, D. A., Hayes, E. B., Campbell, G. L.: Epidemic West Nile encephalitis, New York, 1999: Results of a household-based seroepidemiological survey. Lancet 358, 261-264 (2001).

51. Kaiser, R.: Tick-borne encephalitis. Infect Dis Clin North Am 22, 561-575 (2008).

52. Sa-Ngasang, A., Anantapreecha, S., A-Nuegoonpipat, A., Chanama, S., Wibulwattanakij, S., Pattanakul, K., Sawanpanyalert, P., Kurane, I.: Specific IgM and IgG responses in 
primary and secondary dengue virus infections determined by enzyme-linked immunosorbent assay. Epidemiol Infect 134, 820-825 (2006).

53. Dejnirattisai, W., Supasa, P., Wongwiwat, W., Rouvinski, A., Barba-Spaeth, G., Duangchinda, T., Sakuntabhai, A., Cao-Lormeau, V. M., Malasit, P., Rey, F. A., Mongkolsapaya, J., Screaton, G. R.: Dengue virus sero-cross-reactivity drives antibodydependent enhancement of infection with Zika virus. Nat. Immunol. 17, 1102-1108 (2016).

54. Bardina, S. V., Bunduc, P., Tripathi, S., Duehr, J., Frere, J. J., Brown, J. A., Nachbagauer, R., Foster, G. A., Krysztof, D., Tortorella, D., Stramer, S. L., Garcia-Sastre, A., Krammer, F., Lim, J. K.: Enhancement of Zika virus pathogenesis by preexisting antiflavivirus immunity. Science 356, 175-180 (2017).

55. Barzon, L., Pacenti, M., Franchin, E., Pagni, S., Martello, T., Cattai, M., Cusinato, R., Palu, G.: Excretion of West Nile virus in urine during acute infection. J Infect Dis 208, 1086-1092 (2013).

56. Tan, S. K., Sahoo, M. K., Milligan, S. B., Taylor, N., Pinsky, B. A.: Stability of Zika virus in urine: specimen processing considerations and implications for the detection of RNA targets in urine. J Virol Methods 248, 66-70 (2017).

57. Rios, M., Daniel, S., Chancey, C., Hewlett, I. K., Stramer, S. L.: West Nile virus adheres to human red blood cells in whole blood. Clin Infect Dis 45, 181-186 (2007).

58. Lustig, Y., Mannasse, B., Koren, R., Katz-Likvornik, S., Hindiyeh, M., Mandelboim, M., Dovrat, S., Sofer, D., Mendelson, E.: Superiority of West Nile virus RNA detection in whole blood for diagnosis of acute infection. J Clin Microbiol 54, 2294-2297 (2016).

59. Driggers, R. W., Ho, C. Y., Korhonen, E. M., Kuivanen, S., Jaaskelainen, A. J., Smura, T., Rosenberg, A., Hill, D. A., DeBiasi, R. L., Vezina, G., Timofeev, J., Rodriguez, F. J., Levanov, L., Razak, J., Iyengar, P., Hennenfent, A., Kennedy, R., Lanciotti, R., du Plessis, A., Vapalahti, O.: Zika virus infection with prolonged maternal viremia and fetal brain abnormalities. N Engl J Med 374, 2142-2151 (2016).

60. ECDC: Interim Guidance for Healthcare Providers and Zika Virus Laboratory Diagnosis, 2016. Available at https:/ecdc.europa.eu/sites/portal/files/media/en/publications/Publications/ zika-virus-guidance-healthcare-providers-and-laboratory-diagnosis.pdf

61. Paz-Bailey, G., Rosenberg, E. S., Doyle, K., Munoz-Jordan, J., Santiago, G. A., Klein, L., Perez-Padilla, J., Medina, F. A., Waterman, S. H., Gubern, C. G., Alvarado, L. I., Sharp, T. M.: Persistence of Zika virus in body fluids - Final report. N Engl J Med 379, 1234-1243 (2018).

62. Dejnirattisai, W., Supasa, P., Wongwiwat, W., Rouvinski, A., Barba-Spaeth, G., Duangchinda, T., Sakuntabhai, A., Cao-Lormeau, V. M., Malasit, P., Rey, F. A., Mongkolsapaya, J., Screaton, G. R.: Dengue virus sero-cross-reactivity drives antibodydependent enhancement of infection with Zika virus. Nat Immunol 17, 1102-1108 (2016). 